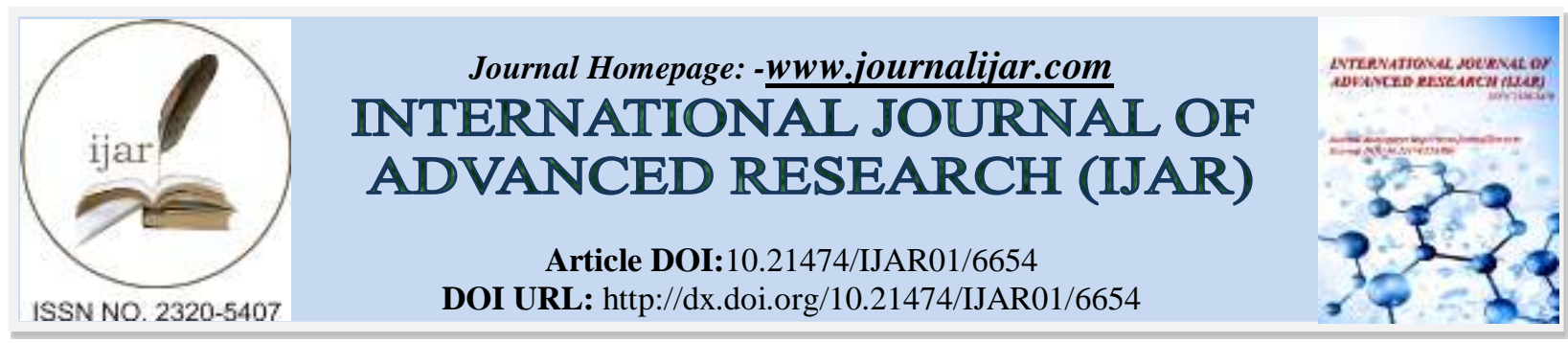

RESEARCH ARTICLE

\title{
FOOT PLACEMENT EFFECTS THE PROPORTION OF MAXIMAL KNEE EXTENSOR MOMENT PRODUCED IN SIT TO STAND AND STAND TO SIT ACTIVITIES.
}

\section{Yusuf Emuk $^{1}$, PT, MSc. Yesim Sengul ${ }^{2}$, PT, PhD, Assoc. Prof.}

1. Katip Celebi University, Faculty of Health Sciences, Department of Physiotherapy and Rehabilitation, Izmir, Turkey.

2. Dokuz Eylul University, School of Physical Therapy and Rehabilitation, Izmir, Turkey.

\section{Manuscript Info}

Manuscript History

Received: 03 January 2018

Final Accepted: 05 February 2018

Published: March 2018

Keywords:-

Sit, stand, knee torque, dominance, foot position.

\begin{abstract}
The sit-to-stand task is a fundamental activity of daily living and a key component of the functional independence. The aim of the study was to identify the effects of foot placement on generated moments during sitto-stand and stand-to-sit activities. Two healthy adults (1M, 1F) volunteered for the study. Isokinetic measurements were conducted by use of Cybex ${ }^{\mathrm{TM}}$ dynamometer. Sit-to-stand performance has been analysed using $\mathrm{CODA}^{\mathrm{TM}} \mathrm{mpx} 30$. $\mathrm{AMTI}^{\mathrm{TM}}$ has been used to measure the force and moment components of foot. The data from sit-to-stand activity has been compared with concentric peak knee extensor moments and the data from stand-to-sit task has been compared with eccentric peak extensor moments. Peak knee extensor moments from Cybex $^{\mathrm{TM}}$ represent maximal achievable force. Knee moments recorded by $\mathrm{CODA}^{\mathrm{TM}}$ has been converted to a proportion of this maximum. Participants had greater peak knee extensor moments in dominant side comparing to non-dominant side in symmetrical and left foot forward positions during sit-to-stand task. When right foot placed forward nondominant side had greater peak knee extensor moments than dominant side. Similar to findings from sit-to-stand tasks, participants had greater peak knee moments in dominant side during feet symmetrical and left foot forward positions during stand-to-sit task performance. This study confirms the generation of a knee extensor moment as a key component for an appropriate sit-to-stand performance. During sit-to-stand, right and left sides produce different amount of torque and before a sit-tostand, positioning the stronger side forward results in an increase in peak knee extensor moment on the weaker side.
\end{abstract}

Copy Right, IJAR, 2018,. All rights reserved.

\section{Introduction:-}

The sit to stand task (STS) is a fundamental activity of daily living and a key component of the functional independence. It has been defined as 'a transitional movement to the upright posture requiring movement of the centre of mass from a stable position to a less stable position over extended lower extremities' (Vander Linden et al., $1994)$. Results of a study has shown that individuals perform $60( \pm 22)$ sit to stand activities each day (Dall and Kerr, 2010). Therefore, it is essential for the aim of maintaining independence in daily life activities (Eriksrud and 
Bohannon, 2003). When the STS ability is impaired, notable functional limitations may occur (Whitney et al., 2005). Impaired STS performance has been demonstrated in the elderly (Dehail et al., 2007), stroke population (Cheng et al., 1998, Lecours et al., 2008), and individuals with Parkinson's Disease (Mak and Hui-Chan, 2008). Impaired STS performance cause higher risk of falling among stroke survivors comparing the same age non-stroke people (Nyberg and Gustafson, 1995, Cheng et al., 1998).

Previous studies have identified that stroke survivors use compensation mechanisms during sit to stand task such as loading unaffected side more and affected side less (Cheng et al., 2001, Brunt et al., 2002). A study examined the effects of foot placement on SitTS and StandTS activities and it was interpreted that positioning the affected foot behind reduces the asymmetry while positioning the unaffected leg forward increases the asymmetry (Roy et al., 2006). One of the major considerations with regards to that study was including the hemiplegics who had relatively high functional level. Therefore, results may not be generalizable for all patients with stroke. Secondly, they only measured vertical reaction forces. However, it is assumed that asymmetry also occurs in the anterior-posterior forces. Another study determined the effect of altering foot position of the dominant limb in healthy participants and the unaffected limb of the participants with hemiplegia on the performance of STS task (Brunt et al., 2002). They measured the vertical and anteroposterior ground reaction forces and bilateral tibialis anterior and quadriceps EMG activity during SitTS task under the spontaneous, limb extended, and limb elevated conditions. The results of the study showed that muscle activity and ground reaction forces can be influenced by altering the initial foot placement of the dominant or unaffected limb (Brunt et al., 2002). With regards to effect of dominance on generated torque, a study determined the results of non-athletes, runner athletes, and jumper athletes and claimed that dominance factor is only significant for non-athletes (Siqueira et al., 2002).

This study aims to identify the effects of foot placement on generated moments during sit to stand and stand to sit activities. Considering evidence from appropriate literature 2 hypotheses have been created.

H1 Dominant side will generate more torque than non-dominant side during Sit to stand and Stand to sit activities.

$\mathrm{H} 2$ Positioning the dominant leg forward will generate more peak moment in non-dominant side comparing to symmetrical position.

\section{Methodology:-}

\section{Participants:-}

One male and one female healthy adult volunteered from the student cohort. Participants' demographics have been taken. Stadiometer has been used to measure height and Weymed ${ }^{\mathrm{TM}}$ BMI Scale has been used to measure weight in $\mathrm{kg}$. Leg dominance determined by spontaneous ball kick. Table 1 shows characteristics of participants.

\begin{tabular}{|l|l|l|}
\hline & Participant 1 & Participant 2 \\
\hline Gender & M & F \\
\hline Age & 25 & 26 \\
\hline Dominant Side & R & R \\
\hline Height $(\mathbf{c m})$ & 173 & 163 \\
\hline Weight (kg) & 88.5 & 57.25 \\
\hline Pelvis Width (cm) & 34.3 & 24.5 \\
\hline Pelvis Depth (cm) & 18.7 & 15 \\
\hline
\end{tabular}

Table 1:- Characteristics of participants

\section{Instrumentation:-}

Isokinetic measurements of knee muscles were conducted by use of a Cybex ${ }^{\mathrm{TM}}$ dynamometer. Sit to Stand performance has been analysed using Cartesian Optoelectronic Dynamic Anthropometer (CODA ${ }^{\mathrm{TM}} \mathrm{mpx}^{30}$ ). AMTI $^{\text {TM }}$ (Advanced Mechanical Technology Inc) has been used to measure the force and moment components of foot.

\section{Procedure:-}

Prior to knee extensor moment measurement participants had a 3-5 minutes warm up sessions using cycle ergometer. Participants have pedalled with no resistance, at a comfortable pace and seat height to ensure warm muscles for maximal testing and prevent injuries (Rodenburg et al., 1994). 


\section{Measurement of Knee Extensor Moment:-}

A Cybex ${ }^{\mathrm{TM}}$ dynamometer has been used to measure the maximum concentric and eccentric strength of knee extensors of right and left leg. The standard protocol for knee extension - flexion tests of Cybex has been followed to assess the knee (Kibler et al., 1991). The used protocol was set up by an experienced lab technician. The tests were performed using the concentric isokinetic mode of testing with velocity at $60^{\circ} / \mathrm{s}$. Participants were instructed to extend the knee against the shin pad during concentric contractions and resist the lever during eccentric contractions. Verbal encouragement for maximal force, and as full a range of motion as possible was provided during the testing procedure. Participants were advised to terminate testing session if they feel any discomfort or pain. The strength was evaluated for the movement ranging from $90^{\circ}$ of flexion to maximal active extension as this replicates the STS movement. Prior to trials, participants practiced 3 repetitions of the knee concentric extension and concentric flexion. After practices, participants performed 5 repetitive trials for each movement. Among the 5 trials of both sets, the highest peak torque (Newton-meters, $\mathrm{Nm}$ ) were obtained for further data analyses as peak torques were needed for this project.

\section{Measurement of Knee Extensor Moment During Sit to Stand Task:-}

Two AMTI force plates were placed under the both feet in order to determine the force and moment components of foot. Cartesian Opto-electronic Dynamic Anthropometer (CODA ${ }^{\mathrm{TM}}$ mpx30) motion analysis system has been used to record the 3-D kinematic data sampled at $240 \mathrm{~Hz}$. Optotrak markers were placed, following the protocol of bilateral gait set, on the both right and left pelvis (PSIS and ASIS), femur (posterior and anterior), tibia (posterior and anterior), knee, ankle, heel and toe. Both systems were integrated to allow analysis of peak extensor torque at thighs off.

The participants were instructed to stand up and sit down with arm crossed on the chest at natural pace and keep their feet at the same position. The chair seat was set at each participant's leg length which was the distance from the lateral femoral condyle to the floor. Base width was $22.5 \mathrm{~cm}$ in all foot positions. It has measured from in between big toes. Participants performed the trials in three different foot positions: (1) symmetrical: both feet placed at $15^{\circ}$ of dorsiflexion; (2) asymmetrical (L): the left foot positioned forward the right foot with $15^{\circ}$ of dorsiflexion at a distance corresponding to a half of participant's foot length; (3) asymmetrical (R): the right foot positioned forward the left foot with $15^{\circ}$ of dorsiflexion at a distance corresponding to a half of participant's foot length. Marks on the thighs and the floor were used for participants in order to keep their foot and seat position between the tasks. One practice was performed before the test and three trials were executed at each foot position. The average of three trials has been used for the further data analysis.

The same examiner has performed the tests for all participants in order to lessen the effects of examiner variability on each of the measurement devices. As stated in Sole et al. (2007), when investigating knee extensor and knee flexor variables, they should be measured by the same investigator.

\section{Data Analysis:-}

Following measurement the peak torque has been identified. This was the highest point on the torque curve regardless of its location in the range of motion. Peak force has been divided to participant's weight in order to normalise data and enable to make a comparison between participants. The data from sit to stand activity has been compared with concentric peak knee extensor moments and the data from stand to sit task has been compared with eccentric peak extensor moments. Peak knee extensor moments from the Cybex ${ }^{\mathrm{TM}}$ represent maximal achievable force. Knee moments recorded by $\mathrm{CODA}^{\mathrm{TM}}$ has been converted to a proportion of this maximum.

\section{Justification of Methodology and Instrumentation:-}

In our study, isokinetic dynamometry testing consisted of five repetitions of maximal concentric and eccentric reciprocal contractions at $60 \%$ s. Previously, it has been shown that angular velocities of 180 and 240 degrees have lower test-retest reliability comparing to 60\% (Burdett and van Swearingen, 1987, Tredinnick and Duncan, 1988). Moreover, it has been recommended that testing procure should include slower velocities when healthy participants are tested (Wilhite et al., 1992).

During concentric phase of quadriceps muscle sit to stand task occurs and eccentric phase results in stand to sit activity (Stein et al., 1999, Petrella et al., 2005). Therefore, comparisons have been made between concentric peak knee extensor moments and sit to stand data, and eccentric peak torque and data from stand to sit task. 
Isokinetic dynamometer has been used to identify concentric and eccentric peak knee extensor moments. Isokinetic dynamometers are often referred to as the gold standard to which all other measurement devices compared (Martin et al., 2006). A fairly recent study has evaluated its reliability and it has been found that isokinetic dynamometer has good test-retest reliability for knee extension ( $\mathrm{ICC}=0.92$ ), and good test-retest reliability for knee flexion $(\mathrm{ICC}=0.89$ ) (Toonstra and Mattacola, 2013).

$\mathrm{CODA}^{\mathrm{TM}}$ motion analysis system has been used to record data during sit to stand and stand to sit activities. Despite there is lack of evidence regarding its reliability and validity for STS task, in a study reliability of kinematic parameters for peak knee extensor has been found to be highly reliable during analysis of gait $($ ICC $=0.84)($ Meldrum et al., 2014). The main advantage of 3-D systems is accuracy. On the other hand, these systems are not effective in terms of time and cost, and they require labs and specific training for users.

\section{Results:-}

Isokinetic Dynamometry:-

Table 2 presents the concentric and eccentric peak knee extensor moments $(\mathrm{Nm})$ and the normalised values of each participant for both sides.

\begin{tabular}{|l|l|l|l|l|l|l|l|l|}
\hline Participant & \multicolumn{2}{l}{$\begin{array}{l}\text { Concentric } \\
(\mathbf{N m})\end{array}$} & \multicolumn{2}{l|l}{$\begin{array}{l}\text { Concentric } \\
(\mathbf{N m} / \mathbf{K g})\end{array}$} & \multicolumn{2}{l|}{$\begin{array}{l}\text { Eccentric } \\
(\mathbf{N m})\end{array}$} & \multicolumn{2}{l|}{$\begin{array}{l}\text { Eccentric } \\
(\mathbf{N m} / \mathbf{K g})\end{array}$} \\
\hline & Left & Right & Left & Right & Left & Right & Left & Right \\
\hline $\mathbf{1 .}$ & 163 & 167 & 1.84 & 1.88 & 262 & 285 & 2.96 & 3.22 \\
\hline 2. & 81 & 130 & 1.41 & 2.27 & 142 & 157 & 2.48 & 2.74 \\
\hline
\end{tabular}

Table 2:- Concentric and eccentric peak knee extensor moments

When normalised concentric peak knee extensor moment in non-dominant side was greater in male participant than female participant (1.84 and 1.41, respectively), in dominant side normalised concentric peak knee extensor moment was in favour of female participant comparing to male participant (2.27 and 1.88, respectively). Peak absolute and normalised eccentric knee extensor moments were greater than absolute and normalised concentric peak knee extensor moments in both sides for both participants. Importantly, dominant sides had greater peak knee extensor moments comparing to non-dominant sides.

\section{Sit to Stand Peak Knee Extensor Moments:-}

Figure 1a shows peak knee extensor moments for participant 1 and Figure $1 \mathrm{~b}$ presents peak knee extensor moments for participant 2 during sit to stand activities in three foot placement conditions.
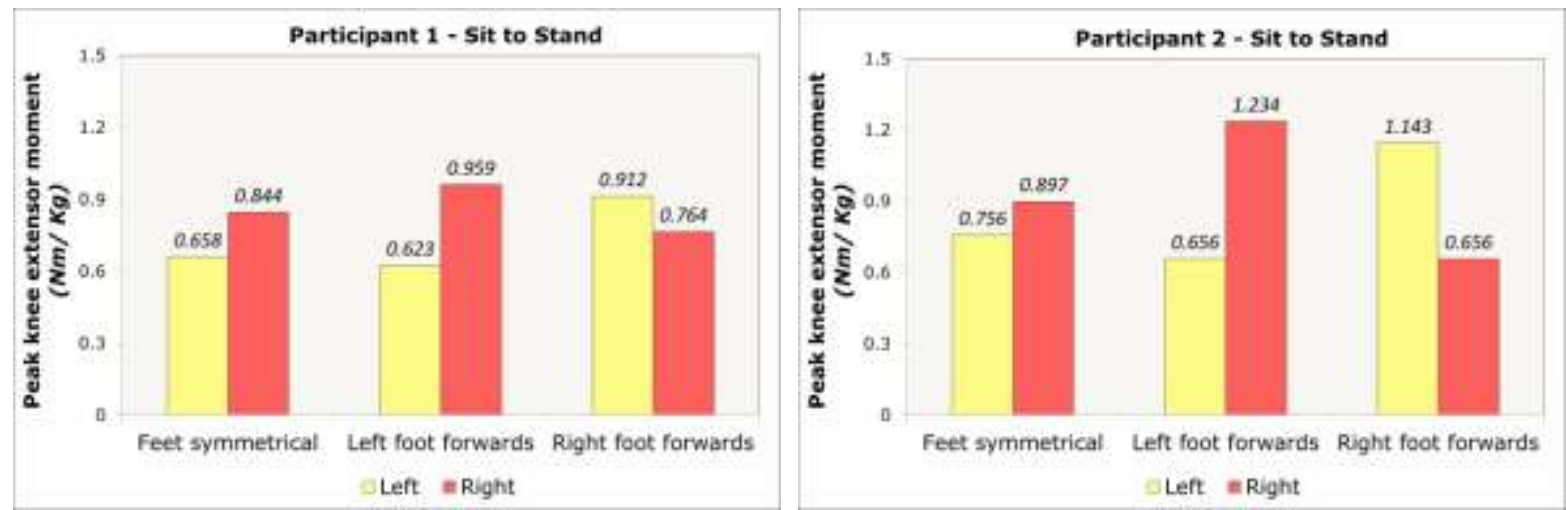

Figure 1a \& 1b:- Peak knee extensor moments during sit to stand

Both participants had greater peak knee extensor moments in dominant side (R) comparing to non-dominant side (L) in symmetrical and left foot forward positions. Additionally, female participant had greater peak knee extensor moments than male participant in these two conditions for both sides. When right foot placed forward non-dominant side had greater peak knee extensor moments than dominant side for both participants. 
Stand to Sit Peak Knee Extensor Moments:-

Figure 2a presents peak knee extensor moments for participant 1 and figure $2 b$ illustrates peak knee extensor moments for participants 2 during stand to sit tasks in three foot placement conditions.
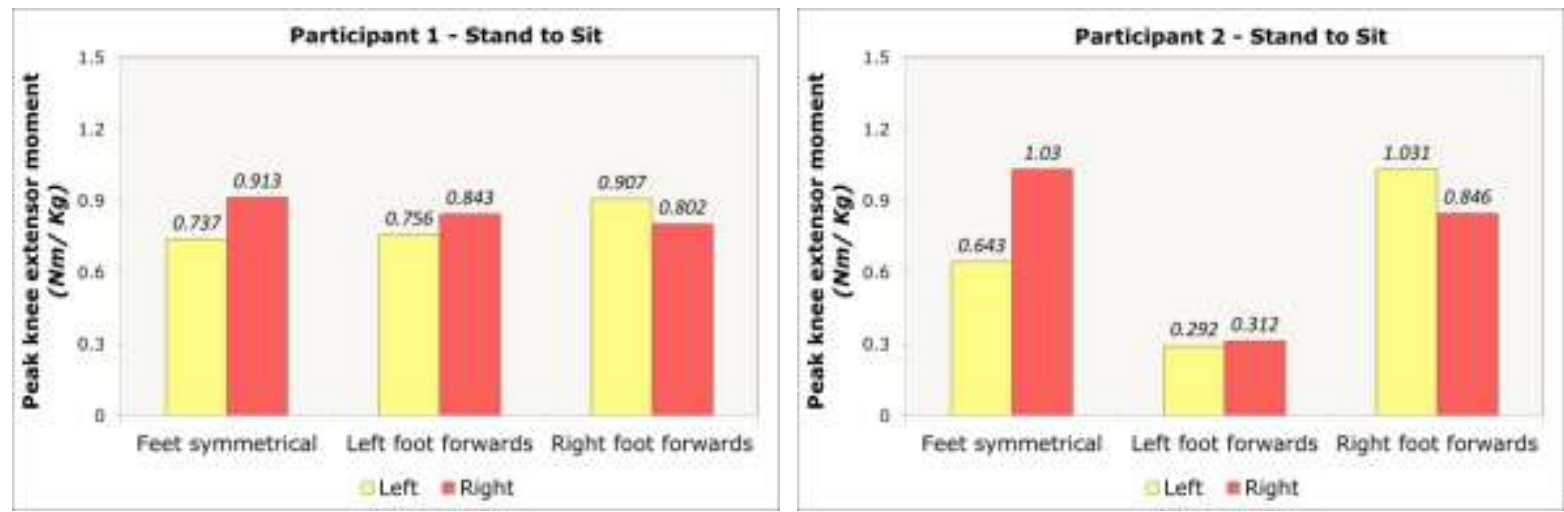

Figure 2 a\&b:- Peak knee extensor moments during stand to sit

Similar to findings from sit to stand tasks, participants had greater peak knee moments in dominant side during feet symmetrical and left foot forward positions. When left foot positioned forward, the male participant had an increase in non-dominant side and a decrease in dominant side in peak knee extensor moments comparing to symmetric foot position. However, the female participant had a decrease in non-dominant side and a decrease in dominant side under the same condition. During dominant foot $(\mathrm{R})$ forward position both participants produced more knee extensor moments in non-dominant side.

Sit to Stand Knee Extensor Moments as a Proportion of Isokinetic Measurement:-

Table 3 presents sit to stand knee moment as a proportion of isokinetic peak knee extensor moment measured by using Cybex ${ }^{\mathrm{TM}}$. In symmetrical position, participants generated more proportion of knee extensor moments in their dominant side comparing to non-dominant side. Both participants had maximum proportion of knee extensor moments in their non-dominant sides when dominant feet placed forward. The mean percentage was $47.82 \%$ in nondominant side at this position. When non-dominant sides placed forward, participants reached the maximum proportion of peak torque in their dominant sides.

\begin{tabular}{|l|l|l|l|l|l|l|}
\hline \multirow{2}{*}{ Participant } & \multicolumn{2}{|l|}{ Feet Symmetrical } & \multicolumn{2}{l|}{ Left Foot Forward } & \multicolumn{2}{l|}{ Right Foot Forward } \\
\cline { 2 - 7 } & Left & Right & Left & Right & Left & Right \\
\hline $\mathbf{1}$ & $35.76 \%$ & $44.893 \%$ & $33.858 \%$ & $51.010 \%$ & $49.565 \%$ & $40.638 \%$ \\
\hline $\mathbf{2}$ & $30.483 \%$ & $32.737 \%$ & $26.451 \%$ & $45.036 \%$ & $46.088 \%$ & $23.941 \%$ \\
\hline Mean & $33.12 \%$ & $38.81 \%$ & $30.15 \%$ & $48.02 \%$ & $47.82 \%$ & $32.29 \%$ \\
\hline SD & 3.73 & 8.60 & 5.23 & 4.22 & 2.45 & 11.80 \\
\hline
\end{tabular}

Table 3:- Proportion of Peak Torque used in Sit to Stand

Stand to Sit Knee Extensor Moments as a Proportion of Isokinetic Measurement:-

Table 4 presents data regarding the percentage of maximum achievable torque during stand to sit task. The mean proportion of peak torque in non-dominant side $25.41 \%$ in symmetric feet position, $18.65 \%$ in left foot forward position, and 36.10 in right foot forward condition. Similar to sit to stand task, non-dominant sides had greater proportion of maximum peak torque when dominant side positioned forward (36.10\%).

\begin{tabular}{|l|l|l|l|l|l|l|}
\hline \multirow{2}{*}{ Participant } & \multicolumn{2}{l|}{ Feet Symmetrical } & \multicolumn{2}{l|}{ Left Foot Forward } & \multicolumn{2}{l|}{ Right Foot Forward } \\
\cline { 2 - 7 } & Left & Right & Left & Right & Left & Right \\
\hline $\mathbf{1}$ & $24.898 \%$ & $28.354 \%$ & $25.540 \%$ & $26.180 \%$ & $30.641 \%$ & $24.906 \%$ \\
\hline $\mathbf{2}$ & $25.927 \%$ & $37.591 \%$ & $11.774 \%$ & $47.883 \%$ & $41.572 \%$ & $30.875 \%$ \\
\hline Mean & $25.41 \%$ & $32.97 \%$ & $18.65 \%$ & $37.03 \%$ & $36.10 \%$ & $27.89 \%$ \\
\hline SD & 0.72 & 6.53 & 9.73 & 15.34 & 7.72 & 4.22 \\
\hline
\end{tabular}

Table 4:- Proportion of Peak Torque used during Stand to Sit 


\section{Discussion:- \\ Interpretation:-}

Common abilities of daily living include the capability of rising from a seated position and to sit down from a standing position (Kralj et al., 1990). STS task requires an adequate postural control and appropriate strategy in order to be performed successfully (Błażkiewicz et al., 2014).

The first hypothesis of present study was that SitTS and StandTS tasks are asymmetrical activities and dominant side and non-dominant side generate different amount of torque. The result of the study confirms that hypothesis. Previously a number of studies suggested that STS task is a symmetrical activity and there is no significant difference between left and right sides (Schenkman et al., 1990, Roebroeck et al., 1994). Roebroeck et al. (1994) tested their participants when the initial knee angle was $105^{\circ}$ flexion at the beginning and hands positioned on hips. They have also used a single force platform. However, it has been clearly demonstrated that arm position affects STS task as well as foot placement and the starting position of knee angle should be $90^{\circ}$ of flexion (Kwong et al., 2014). Moreover, use of a force platform for each foot provides more robust data. Additionally, results from different studies also validate our results and explain right and left sides of a body produce unequal total of peak knee extensor moments (Brunt et al., 2002, Roy et al., 2006). However, our study had only two participants while Brunt et al. included 10 healthy and 10 hemiplegic subjects and Roy et al. included a total of 12 participants with chronic hemiparesis. Therefore, their results are likely to be more generalisable comparing to our findings.

The second hypothesis was that position of foot had an effect on generated torque. The results of the study illustrate that comparing to feet symmetrical condition, dominant side generate more torque when non-dominant side positioned forward and non-dominant side had greater peak knee extensor moment when dominant side was forward. The results of the study validate our hypothesis. Moreover, in the literature, a great number of studies have similar findings with our study and it has been clearly shown that foot position affects STS task with regards generated torque (Brunt et al., 2002, Janssen et al., 2002, Roy et al., 2006, Roy et al., 2007, Wang and Newell, 2012). A study with 12 participants evaluated the effects of altered foot position on peak knee extensor moments during SitTS and StandTS tasks (Roy et al., 2007). Their results showed that while positioning the unaffected leg forward, affected side generates more knee extensor moment than spontaneous, symmetrical, and affected leg forward positions. Despite the fact that they fail to examine the joint moments in the sagittal plane alone, our results are in agreement with their findings.

\section{Clinical Implication:-}

Sit to stand is a common task which stroke patients face a difficulty to perform. The results of our study show that by positioning feet in an appropriate position more peak knee extensor moment may be generated. Producing more torque may result in a proper STS performance and this may assist to increase stroke survivors' functional capacity and make them more independent. Also, directing this aim with task specific repetitive training approaches look to have a potential positive effect on patients suffering difficulty to perform STS task. Lastly, positioning the feet in an appropriate position does not require specific equipment or training. Therefore, it is an easy and practical approach to use in clinical area.

\section{Limitations:-}

Our study had a small sample size and there were only two participants who performed the tests. Thus, the results of the study may not be generalisable. Eyeballing alignment of sensors and eyeballing the peak moment from the graph are time consuming. The test requires modern devices. Therefore, this is an expensive method to use. Prior to sit to stand both feet lifted off the floor to check if the system works but foot placement has not been controlled after this procedure. The placement of landmarks may be changed during tasks.

\section{Conclusion:-}

Despite the fact that STS is an easy activity for healthy normal people, a number of groups of people such as elderly and stroke survivors have a difficulty to perform the task successfully. The present study confirms the generation of a knee extensor moment as a key component for an appropriate STS performance. During STS task, right and left sides of the body produce different amount of torque and before performing a STS positioning the stronger side results in an increase in peak knee extensor moment on the weaker side. Despite the sample size was small in this study, it has similar results with studies had larger sizes in the literature. Therefore, the results of the study may be moved into clinical area and physiotherapists may use this approach in their practise. 


\section{Acknowledgement:-}

We would like to thank to Assistant Professor Marjan Blackburn for giving her valuable time and criticism throughout the project.

\section{Funding:-}

This research received no specific grant from any funding agency in the public, commercial, or not-for-profit sectors.

\section{Declaration of Conflicting Interests:-}

The authors declares that there is no conflict of interest.

\section{References:-}

1. BŁAŻKIEWICZ, M., WISZOMIRSKA, I. \& WIT, A. 2014. A new method of determination of phases and symmetry in stand-to-sit-to-stand movement. International journal of occupational medicine and environmental health, 27, 660-671.

2. BRUNT, D., GREENBERG, B., WANKADIA, S., TRIMBLE, M. A. \& SHECHTMAN, O. 2002. The effect of foot placement on sit to stand in healthy young subjects and patients with hemiplegia. Archives of physical medicine and rehabilitation, 83, 924-929.

3. BURDETT, R. G. \& VAN SWEARINGEN, J. 1987. Reliability of Isokinetic Muscle Endurance Tests*. Journal of Orthopaedic \& Sports Physical Therapy, 8, 484-488.

4. CHENG, P.-T., LIAW, M.-Y., WONG, M.-K., TANG, F.-T., LEE, M.-Y. \& LIN, P.-S. 1998. The sit-to-stand movement in stroke patients and its correlation with falling. Archives of physical medicine and rehabilitation, 79, 1043-1046.

5. CHENG, P.-T., WU, S.-H., LIAW, M.-Y., WONG, A. M. K. \& TANG, F.-T. 2001. Symmetrical body-weight distribution training in stroke patients and its effect on fall prevention. Archives of physical medicine and rehabilitation, 82, 1650-1654.

6. DALL, P. M. \& KERR, A. 2010. Frequency of the sit to stand task: An observational study of free-living adults. Applied Ergonomics, 41, 58-61.

7. DEHAIL, P., BESTAVEN, E., MULlER, F., MALlET, A., ROBERT, B., BOURDEL-MARCHASSON, I. \& PETIT, J. 2007. Kinematic and electromyographic analysis of rising from a chair during a "Sit-to-Walk" task in elderly subjects: Role of strength. Clinical Biomechanics, 22, 1096-1103.

8. ERIKSRUD, O. \& BOHANNON, R. W. 2003. Relationship of knee extension force to independence in sit-tostand performance in patients receiving acute rehabilitation. Physical Therapy, 83, 544-551.

9. JANSSEN, W. G. M., BUSSMANN, H. B. J. \& STAM, H. J. 2002. Determinants of the Sit-to-Stand Movement: A Review. Physical Therapy, 82, 866-879.

10. KIBLER, W. B., GOLDBERG, C. \& CHANDLER, T. J. 1991. Functional biomechanical deficits in running athletes with plantar fasciitis. The American Journal of Sports Medicine, 19, 66-71.

11. KRALJ, A., JAEGER, R. J. \& MUNIH, M. 1990. Analysis of standing up and sitting down in humans: definitions and normative data presentation. Journal of biomechanics, 23, 1123-1138.

12. KWONG, P. W. H., NG, S. S. M., CHUNG, R. C. K. \& NG, G. Y. F. 2014. Foot placement and arm position affect the five times sit-to-stand test time of individuals with chronic stroke. BioMed research international, 2014.

13. LECOURS, J., NADEAU, S., GRAVEL, D. \& TEIXERA-SALMELA, L. 2008. Interactions between foot placement, trunk frontal position, weight-bearing and knee moment asymmetry at seat-off during rising from a chair in healthy controls and persons with hemiparesis. Journal of rehabilitation medicine, 40, $200-207$.

14. MAK, M. K. Y. \& HUI-CHAN, C. W. Y. 2008. Cued task-specific training is better than exercise in improving sit-to-stand in patients with Parkinson's disease: A randomized controlled trial. Movement Disorders, 23, 501509.

15. MARTIN, H. J., YULE, V., SYDDALl, H. E., DENNISON, E. M., COOPER, C. \& AIHIE SAYER, A. 2006. Is hand-held dynamometry useful for the measurement of quadriceps strength in older people? A comparison with the gold standard Biodex dynamometry. Gerontology, 52, 154-159.

16. MELDRUM, D., SHOULDICE, C., CONROY, R., JONES, K. \& FORWARD, M. 2014. Test-retest reliability of three dimensional gait analysis: Including a novel approach to visualising agreement of gait cycle waveforms with Bland and Altman plots. Gait \& Posture, 39, 265-271. 
17. NYBERG, L. \& GUSTAFSON, Y. 1995. Patient Falls in Stroke Rehabilitation A Challenge to Rehabilitation Strategies. Stroke, 26, 838-842.

18. PETRELlA, J. K., KIM, J.-S., TUGGLE, S. C., HALL, S. R. \& BAMMAN, M. M. 2005. Age differences in knee extension power, contractile velocity, and fatigability. Journal of Applied Physiology, 98, 211-220.

19. RODENBURG, J. B., STEENBEEK, D., SCHIERECK, P. \& BÄR, P. R. 1994. Warm-up, stretching and massage diminish harmful effects of eccentric exercise. International Journal of sports medicine, 15, 414-419.

20. ROEBROECK, M. E., DOORENBOSCH, C. A. M., HARLAAR, J., JACOBS, R. \& LANKHORST, G. J. 1994. Biomechanics and muscular activity during sit-to-stand transfer. Clinical Biomechanics, 9, $235-244$.

21. ROY, G., NADEAU, S., GRAVEL, D., MALOUIN, F., MCFADYEN, B. J. \& PIOTTE, F. 2006. The effect of foot position and chair height on the asymmetry of vertical forces during sit-to-stand and stand-to-sit tasks in individuals with hemiparesis. Clinical Biomechanics, 21, 585-593.

22. ROY, G., NADEAU, S., GRAVEL, D., PIOTTE, F., MAlOUIN, F. \& MCFADYEN, B. J. 2007. Side difference in the hip and knee joint moments during sit-to-stand and stand-to-sit tasks in individuals with hemiparesis. Clinical Biomechanics, 22, 795-804.

23. SCHENKMAN, M., BERGER, R. A., RILEY, P. O., MANN, R. W. \& HODGE, W. A. 1990. Whole-Body Movements During Rising to Standing from Sitting. Physical Therapy, 70, 638-648.

24. SIQUEIRA, C. M., PELEGRINI, F. R. M. M., FONTANA, M. F. \& GREVE, J. M. D. 2002. Isokinetic dynamometry of knee flexors and extensors: comparative study among non-athletes, jumper athletes and runner athletes. Revista do Hospital das Clínicas, 57, 19-24.

25. STEIN, R. B., MOMOSE, K. \& BOBET, J. 1999. Biomechanics of human quadriceps muscles during electrical stimulation. Journal of Biomechanics, 32, 347-357.

26. TOONSTRA, J. \& MATTACOLA, C. G. 2013. Test-Retest Reliability and Validity of Isometric Knee-Flexion and-Extension Measurement Using 3 Methods of Assessing Muscle Strength. Journal of sport rehabilitation.

27. TREDINNICK, T. J. \& DUNCAN, P. W. 1988. Reliability of measurements of concentric and eccentric isokinetic loading. Physical Therapy, 68, 656-659.

28. VANDER LINDEN, D. W., BRUNT, D. \& MCCULLOCH, M. U. 1994. Variant and invariant characteristics of the sit-to-stand task in healthy elderly adults. Archives of physical medicine and rehabilitation, 75, 653-660.

29. WANG, Z. \& NEWELL, K. M. 2012. Asymmetry of foot position and weight distribution channels the inter-leg coordination dynamics of standing. Experimental brain research, 222, 333-344.

30. WHITNEY, S. L., WRISLEY, D. M., MARCHETTI, G. F., GEE, M. A., REDFERN, M. S. \& FURMAN, J. M. 2005. Clinical Measurement of Sit-to-Stand Performance in People With Balance Disorders: Validity of Data for the Five-Times-Sit-to-Stand Test. Physical Therapy, 85, 1034-1045.

31. WILHITE, M. R., COHEN, E. R. \& WILHITE, S. C. 1992. Reliability of concentric and eccentric measurements of quadriceps performance using the KIN-COM dynamometer: the effect of testing order for three different speeds. Journal of Orthopaedic \& Sports Physical Therapy, 15, 175-182. 